\title{
SOBRE PARALOGISMOS: IDEAS PARA TENER EN CUENTA
}

\author{
LUIS VEGA REÑóN \\ Departamento de Lógica, Historia y Filosofía de la Ciencia \\ Universidad Nacional de Educación a Distancia (UNED) \\ lvega@fsof.uned.es
}

RESUMEN: En este artículo me propongo dos tareas. (1) Mostrar la singularidad de los paralogismos según Vaz Ferreira dentro de la tradición de las falacias, debida no sólo a su peculiar marco "psico-lógico" de planteamiento, sino a su concepción del paralogismo como un proceso o estado de confusión y una fuente de errores mentales y cognitivos antes que discursivos. (2) Trasladar esta idea al campo actual de la argumentación para aprovechar su poder de sugerencia, pues la contribución de Vaz Ferreira no se limita a la lúcida exploración e ilustración del paralogismo como una dimensión del discurrir falaz, antes de él apenas entrevista. Además abunda en propuestas dignas de tenerse en cuenta en nuestras discusiones actuales en torno a la argumentación falaz.

PALABRAS CLAVE: Vaz Ferreira, Lógica viva, teoría de argumentación, argumentación falaz

SUMmaRY: This paper has two aims. (1) To show the singularity of Vaz Ferreira's idea of paralogisms inside the fallacy tradition, due not only to his "psycho-logic" frame of approach, but to his conception of the paralogism as a process or state of confusion and a source of mistakes that are mental and cognitive rather than discursive. (2) To translate this idea to the present-day field of argumentation so as to take advantage of Vaz's power of suggestion. For his contribution is not confined to the lucid exploration and illustration of the paralogism as a dimension of fallacies barely noticed before him, but also abounds with suggestions worth taking into account in our current discussions about fallacious argumentation.

KEY WORDS: Vaz Ferreira, Lógica viva, argumentation theory, fallacious argumentation

En este artículo revisaré algunos tópicos en torno a la argumentación falaz a partir de unas sugerencias de Carlos Vaz Ferreira (Montevideo, 1872-1958). No es, por cierto, un autor de culto en los estudios actuales sobre lógica informal o sobre argumentación. Pero supongo que, entre nosotros, en nuestro medio hispánico, tampoco será preciso detenerse a justificar su adopción como autor de referencia. Recordemos simplemente la importancia de su autodenominada "Psico-Lógica" para la historia - aún por escribir — de la lógica informal hispana y, en particular, la significación de los ensayos que componen su Lógica viva dentro del estudio específico de las falacias. Pues bien, es su legado en este terreno el que ahora interesa. Y de él son dos cosas las que aquí me gustaría destacar: la singularidad de su concepción del paralogismo dentro de la larga tradición de las 
falacias; y el poder de sugerencia de sus ideas, una vez trasladadas al campo actual de la argumentación, para las discusiones en curso acerca de la argumentación falaz.

\section{El legado de Vaz Ferreira}

El título del artículo alude a Vaz Ferreira en un doble sentido: tanto con respecto al tema, los paralogismos, como en relación con su tratamiento, no por reducción a un sistema, a una teoría o una taxonomía sistemáticas, sino a través de unas ideas que se deben tener en cuenta. La sensibilidad de Vaz hacia los paralogismos como confusiones o errores mentales y cognitivos antes que discursivos hace de él una figura singular dentro de la tradición de las falacias. Y la distinción entre "pensar por sistemas" y "pensar por ideas para tener en cuenta" es justamente uno de los puntos introducidos por su Lógica viva. Al pensar por sistemas nos remitimos a algo destinado a aplicarse o cumplirse en todos los casos; al pensar por ideas observamos o anotamos algo que convendrá tener en cuenta cuando se trate o se reflexione sobre el particular. Podemos emplear el primer procedimiento, recurrir a sistemas, cuando disponemos de todos los principios y hechos pertinentes sobre el asunto tratado; unos y otros se dejan integrar en un razonamiento general y los casos estudiados son iguales u homogéneos, según puede ocurrir en ciencias como las matemáticas o la mecánica — apunta Vaz-. El otro es, en cambio, el procedimiento indicado cuando hemos de tratar con cuestiones de grado y de matiz, y con casos concretos, dispares y particulares como los paralogismos de que vamos a ocuparnos. Hoy estamos familiarizados con la resistencia de las falacias a un tratamiento uniforme y sistemático, bien en un sentido fuerte, es decir, por remisión a una teoría general de la argumentación falaz, o bien en un sentido débil, por referencia a un catálogo cabal o una clasificación comprensiva de sus tipos y variantes. Desde los años 1970 es costumbre afirmar que no hay una teoría de las falacias. Pero de mucho antes data la convicción de que no cabe encasillar las múltiples maneras como los hombres pueden equivocarse o engañarse cuando discurren o argumentan. ¿Qué ideas de Vaz Ferreira conviene tener en cuenta a este respecto? Algunos puntos sustanciales de su legado podrían resumirse como sigue.

Para empezar, contamos con una aportación táctica — digamosque tiene que ver con el planteamiento de los casos considerados: consiste en abandonar la vía tradicional de los tipos y las clases de falacias para fijarse en los usos y las disposiciones falaces que presen- 
tan multitud de ejemplos tomados de la práctica común y cotidiana en diversos géneros de discurso público (e.g., periodístico, parlamentario, académico). Así pues, frente a la consideración lógica abstracta de cómo uno podría o debería equivocarse, la Lógica viva pasa a considerar cómo, efectivamente, la gente se equivoca y cómo se muestra de ordinario predispuesta a hacerlo. Ahora bien, este desplazamiento táctico del foco de atención, este giro desde las falacias de catálogo hasta nuestras prácticas falaces, responde a ciertos supuestos estratégicos más innovadores y profundos. Dos de estos supuestos merecen a mi juicio mayor atención.

El primero de esos supuestos guarda relación con la idea básica de paralogismo. Se funda en la revisión de la propuesta avanzada por la Lógica de Mill ${ }^{1}$ de una clase inédita de falacias: las falacias de confusión o errores discursivos cometidos por un pensamiento confuso e indistinto como el que incurre inadvertidamente en ambigüedad, petición de principio o ignorancia de la cuestión - fallos que, una vez advertidos, pueden parecer sorprendentes en un espíritu sano-. Vaz hace notar que no constituyen en realidad una clase determinada de falacias, sino un modo de caer en ellas, sea cual sea su clase. Así, "habrá diversos modos psicológicos de caer en las falacias: sin razonar o casi sin razonar [...]; razonando muy confusamente, menos confusamente, y así por grados hasta el caso en verdad menos común del mal raciocinio distintamente concebido" (Vaz 1908, p. 177). Por lo demás, su comisión no sólo revelaría incompetencia, poca inteligencia o falta de instrucción, pues tales paralogismos también pueden darse de forma "incipiente, indecisa, subdiscursiva" en mentes preparadas (Vaz 1908, p. 177). Estas observaciones llevan a reconocer diversos modos de incurrir en usos —o de hallarse en estados — paralogísticos, en particular: $(a)$ un modo explícitamente discursivo; $(b)$ un modo confuso pero explicitable; $(c)$ un modo confuso e irreducible al discurso expreso o, al decir de Vaz, "subdiscursivo" o "prediscursivo", que según él sería, por cierto, el más común y característico. ${ }^{2}$

El segundo supuesto, de carácter más general, responde a una profunda convicción formulable en estos términos: "lo que expresamos es una mínima parte de lo que pensamos y lo que pensamos es una mínima parte de lo que psiqueamos [es decir, de lo que vivimos intelectual, sensitiva y afectivamente]". " De este supuesto se desprende un par de ideas básicas de la "Psico-Lógica" de Vaz: (i) ni

\footnotetext{
${ }^{1}$ Véase Mill 1917, libro V, cap. II, §2, pp. 730-731, y cap. VII, pp. 806-831).

${ }^{2}$ Véase Palladino 1962, en especial las pp. 170, 173.

${ }^{3}$ Cfr. el prólogo de Manuel Claps a la edición de Vaz 1979, p. xxii.
} 
los esquemas verbales, ni menos aún los patrones lógicos, pueden imponerse y ahormar los procesos psicológicos; (ii) hay una lógica pre- o subdiscursiva ignorada o desatendida por la lógica tradicional. Ambas ideas se oponen a la pretensión clásica del análisis lógico de atenerse al razonamiento expreso ( $\mathrm{Vaz} 1945$, p. 190), que es por cierto una directriz congruente con la concepción tradicional de los sofismas como falacias clara y distintamente concebidas (Vaz 1979, pp. 176-177). Frente a esta idea de sofisma, los paralogismos que a Vaz Ferreira le importa detectar y examinar vienen a ser procesos por los que caemos o nos encontramos en estados de neblina que tiñen, velan o enturbian nuestra mente, "nos impiden ver y pensar con justeza" (1945, p. 135). "En otros términos, tampoco muy precisos, cabría hablar no sólo de confusiones, sino de disposiciones o predisposiciones ideológicas, y así remontarse a otros precedentes como los ídolos (Bacon) o los prejuicios (Helvetius), o de marcos estereotipados, en la ola del análisis contemporáneo del discurso.

\section{Sofismas y paralogismos}

Llegados a este punto, conviene recordar una antigua diversificación de las falacias entre sofismas y paralogismos. Según esta tradición, un sofisma es un ardid o una argucia dolosa, mientras que un paralogismo es un error involuntario, un fallo o un descuido. Pues bien, en aras de la tradición, propongo que nos imaginemos el campo de la argumentación como un terreno donde medran tanto las buenas como las malas hierbas. Entre las malas figuran las múltiples variedades de la argumentación falaz que cubren desde el yerro más ingenuo debido a incompetencia o a inadvertencia, en el extremo del paralogismo, hasta el engaño urdido subrepticia y deliberadamente en el extremo opuesto del sofisma. Aunque haya variantes que se solapen o se muestren a veces graduales e indecisas, hasta el punto de que el espectro de la argumentación falaz parezca extenderse como una especie de continuo, no se borra la distinción y distancia entre ambos extremos, al igual que una gama de colores grises no difumina la diferencia entre el blanco y el negro.

En este marco, según otra presunción habitual de la tradición lógica, las falacias más relevantes son las que tienden al polo de los

\footnotetext{
${ }^{4}$ En ocasiones, Vaz lamenta verse obligado a esta suerte de expresiones metafóricas para dar cuenta de los fenómenos confusos e innominados aludidos: "Me desespera tener que usar estas metáforas <'teñir', 'velar', 'enturbiar', etc.>: el lector querrá interpretarlas de acuerdo con la buena psicología” (1979, p. 177). Cfr. también una acotación en sentido análogo a propósito de lo que, en otro contexto, denomina "instinto lógico" o "buen sentido hiperlógico" (1945, p. 194, n. 1).
} 
sofismas efectivos y con éxito, es decir las estrategias capciosas que logran confundir o engañar al receptor del discurso, sea un interlocutor, un jurado o un auditorio. El secreto de su importancia radica, en principio, en su interés y su penetración crítica; por ejemplo, gracias a esta idea de sofisma podemos detectar no sólo el recurso a argumentos espurios, sino la manipulación falaz de formas correctas de razonamiento - análogamente a como podemos reconocer el discurso que trata de engañar incluso con la verdad-; y dando un paso más, podemos advertir no sólo sus efectos perversos sobre la inducción de creencias o disposiciones, sino su contribución a minar la confianza básica en los usos del discurso. Pero su importancia también estriba en lo que unos sofismas cumplidos nos revelan acerca de la argumentación en general. Baste observar, por ejemplo, que en tales casos la argumentación falaz se perpetra y desenvuelve en un marco no sólo discursivo sino interactivo, y de modo que la dualidad de sofismas y paralogismos presenta una curiosa correlación donde el éxito de un sofisma cometido por un emisor trae aparejada la comisión de un paralogismo por parte de un receptor, así que la complicidad del receptor no deja de ser codeterminante de la suerte del argumento. Más aún, como es difícil que una misma persona se encuentre al mismo tiempo en ambos extremos del arco de la argumentación falaz, el sofístico y el paralogístico (pues nadie en sus cabales logrará engañarse ingenua y subrepticiamente a la vez a sí mismo), ${ }^{5}$ entonces la eficacia del sofisma típico comporta la efectividad de la interacción correspondiente entre los diversos agentes involucrados. En cambio, no tiene por qué ocurrir así en el caso de los paralogismos, puesto que no todo paralogismo es el resultado de una estrategia deliberadamente engañosa, ni para su comisión es necesario contar con la intervención de otro agente distinto del que incurre en la confusión o el fallo discursivo. En suma, los sofismas no sólo descansan en maniobras o estrategias dolosas, sino que, más allá de la crítica lógica, suponen unas dimensiones de interacción y de inducción sobre los receptores

\footnotetext{
${ }^{5}$ Aunque uno pueda transitar más o menos clara o confusamente entre los extremos del arco. Así como no se excluye la existencia de múltiples casos intermedios entre ambos extremos, el sofístico y el paralogístico, tampoco cabe excluir la de otros casos no infrecuentes en los que uno puede - e incluso a veces quiereengañarse a sí mismo. Todo esto supone cierta analogía de la idea de sofisma con una concepción clásica de la mentira, de raíz agustiniana, y remite a la discusión abierta en torno al "autoengaño", puntos en los que ahora no puedo detenerme pese a su interés discursivo y cognitivo. Sobre el estado actual de esta discusión, véase el reciente monográfico de Teorema "Autoengaño: problemas conceptuales" (vol. 26, no. 3,2007$)$.
} 
del discurso abiertas a las perspectivas dialéctica y retórica sobre la argumentación.

Ahora bien, la consideración de los casos o estados paralogísticos también tiene una significación especial, y tanto la diagnosis como el estudio de algunas modalidades y de sus efectos deletéreos, en una variedad de ejemplos y contextos, son méritos distintivos de la Lógica viva. Dicha significación no sólo se deriva de la frecuencia y la "naturalidad" de los propios paralogismos, ni se debe únicamente a las lúcidas observaciones de Vaz sobre algunas variedades típicas, como la falsa oposición, la falsa precisión, las confusiones del trato de cuestiones normativas como si fueran explicativas, o las trampas subyacentes en la sistematización del pensamiento o en el esquematismo del lenguaje. La significación de los paralogismos también tiene que ver con otras sugerencias del planteamiento "psico-lógico" de Vaz sobre diversos aspectos de nuestras prácticas argumentativas, como los cognitivos por ejemplo. Para apreciarla, será bueno partir de una muestra concreta: valga el paralogismo de la falsa oposición aunque nada más sea por ser el primer caso estudiado en la Lógica viva - aparte de venir ilustrado con multitud de ejemplos y lujo de detalles-.

\section{La falsa oposición}

Es una de las falacias más comunes, y por la cual se gasta en pura pérdida la mayor parte del trabajo pensante de la humanidad, la que consiste en tomar por contradictorio lo que no es contradictorio; en crear falsos dilemas, falsas oposiciones. Dentro de esta falacia, la muy común que consiste en tomar lo complementario por contradictorio no es más que un caso particular de ella, pero un caso prácticamente muy importante. (Vaz 1945, p. 11; las cursivas son del original.)

Además se trata de un paralogismo que puede presentarse bajo formas no sólo burdas y evidentes, sino celadas y sutiles: así, tras ofrecer unas primeras muestras flagrantes de disyuntivas forzadas o indebidamente excluyentes, Vaz hace notar: "Ahora, debo advertirles que, en la mayoría de los casos prácticos, nuestro paralogismo no se ve tan claramente. En la realidad, lo que hace la falacia de falsa oposición es, sobre todo, confundir más o menos, como sombrear las cuestiones" (1945, p. 18). Nos encontramos, en definitiva, ante un paralogismo de confusión típico.

En la Lógica viva, Vaz presenta tres variedades principales: (1) una, muy genérica, consiste en tomar por opuestos contradictorios 
dos extremos que son más bien contrarios o simplemente dispares pero no irreconciliables; las otras dos, más específicas, son (2) el falso dilema de juzgar excluyentes entre sí los casos complementarios, y (3) el descarte empeñado en tratar como incompatibles los factores o elementos concurrentes en un caso complejo. (Vaz, en otros momentos y lugares, también se ocupará de otros paralogismos relacionados con la contradicción y de otros casos distintos de contraposición, por ejemplo, entre los ideales que llama "interferentes", i.e., fines o valores en conflicto irreducible.)

La modalidad primera (1) no parece atraer especialmente la atención de la Lógica viva, aunque la historia de la filosofía viene cargada de ejemplos a partir del paradigma de falsa oposición que representan los primeros versos de la revelación de la diosa en el Poema de Parménides. Recordemos que, a juicio de Parménides o a tenor de lo que la diosa declara, sólo cabe concebir dos caminos de investigación acerca del ser: (i), que es y no es posible que no sea, i.e., la vía de la verdad bien redonda, y (ii) que no es y es necesario que no sea, i.e., la vía de lo absolutamente incognoscible e inescrutable (28 B 2, 3-5). Luego, no queda sino un único camino pensable o practicable, que es y no es posible no ser (28 B 8 1-2). Pero huelga decir que, entre los dos extremos contrapuestos, caben efectivamente otros casos no considerados, como el de que no es necesario que sea y el de que no es necesario que no sea; casos que abren, en suma, la vía de la contingencia frente a las dos vías anteriores de la necesidad de ser y la necesidad de no ser. Así pues, lejos de que los extremos iniciales de lo que es y lo que no es sean contradictorios, no pasan de resultar — dentro de su imprecisión - contrarios y, en definitiva, no llegan a determinar esa suerte de silogismo disyuntivo que el Poema pretende: no establecen la disyunción excluyente sobre la que Parménides quiere sentar, dada la imposibilidad e inaceptabilidad absoluta del no ser, la imperiosa necesidad del ser. Por lo demás, la posibilidad — después reconocida (28 B 851 ss.) — del parecer de los bicéfalos o aturdidos sobre lo que es y no es, se refiere a otro género de fenómenos, el cosmológico, y pertenece a otro dominio cognitivo y expresivo, el de las opiniones de los mortales. Es obvio que este reconocimiento, en vez de corregir o atenuar la contraposición de partida, se suma a ella y viene a suplementarla en este otro dominio. ${ }^{6}$

Frente a la ausencia de muestras y análisis de paralogismos de este tipo, debida quizás a su carácter más escolar y abstracto, Vaz

${ }^{6}$ Pueden verse los textos de Parménides en la edición y versión de Eggers y Juliá (1978, pp. 477-479, 481, en particular). 
prodiga detalles y ejemplos a propósito de las otras dos modalidades específicas. Una buena muestra de los paralogismos excluyentes de tipo (2) podría ser la generada en torno a una propuesta que expuso él mismo en el Consejo Universitario: Vaz proponía hacer obligatoria, durante el bachillerato, la lectura de obras originales, prestadas por la Universidad, para familiarizar a los estudiantes con los grandes autores y elevar el nivel de enseñanza. La propuesta suscitó una discusión entre los colegas que compartían ambos objetivos, pero discrepaban de los medios al respecto: uno alegaba que el verdadero procedimiento para ese fin era organizar conferencias; otro se oponía señalando que el procedimiento indicado consistía en que fueran los profesores quienes hicieran las lecturas en clase. "Y así continuaron varios miembros del Consejo proponiendo procedimientos, cada uno de los cuales, para el que lo proponía, era el procedimiento, el único que debía adoptarse" (1945, pp. 26-27). Pero es evidente que muchas de las medidas propuestas, lejos de ser excluyentes entre sí, podían resultar complementarias.

Por otro lado, una buena ilustración de los paralogismos de falsa oposición de tipo (3), que descartan los casos codeterminantes en atención al caso que se considera única o verdaderamente decisivo, sería la discusión que Vaz recoge y esquematiza en torno al problema del origen de las nacionalidades: "¿Qué es lo que hace verdaderamente una nacionalidad? - La raza — nos dice una escuela. —No — dice otra: las condiciones geográficas y geológicas. - Tampoco es cierto - dice una tercera: lo que hace las nacionalidades es la comunidad de religión. - Falso — dice una cuarta: lo que hace las nacionalidades es la comunidad de leyes. Y para otra será la comunidad de idioma, etc." (1945, pp. 40-41). Ahora bien, observa Vaz, la nacionalidad es "un algo" complejo y vago en cuya formación y explicación entran todos esos factores, aunque en proporciones distintas no sólo en general sino según los casos; así pues, quien sólo reconozca un factor y rechace la contribución o cooperación de los demás, "se condena fatalmente a pensar mal" (1945, p. 41).

La perspectiva analítica de Vaz sobre los paralogismos de falsa oposición presenta además otros dos rasgos originales y característicos. Uno estriba en la consideración de las relaciones mutuas o, digamos, contaminaciones entre los diversos tipos de paralogismos detectados. El otro, en la atención a sus proyecciones o secuelas tanto teóricas como prácticas, es decir, tanto en relación con las cuestiones planteadas o tratadas en el plano del pensamiento y del discurso, como en relación con los problemas por resolver o los asuntos por decidir en el terreno de la acción. La consideración de las posibles interrelaciones 
o complicidades entre la falsa oposición y otros paralogismos cuadra con la intención de Vaz de tratar con disposiciones, usos o estados falaces concretos, antes que con clases generales o patrones abstractos de falacias. Por ejemplo, en el análisis de los errores provocados por la confusión entre las cuestiones explicativas y las normativas, Vaz no deja de señalar la incidencia de la falsa oposición en diversos momentos del examen de una cuestión normativa que demanda una resolución o una decisión práctica: así, en la consideración inicial de las opciones o soluciones posibles, puede propiciar la reducción del abanico de posibilidades a una sola o el descarte de las opciones graduadas o combinadas a partir de las disponibles al principio (1945, pp. 79, 83); asimismo, en el segundo momento de escrutinio de las ventajas e inconvenientes de las soluciones contempladas, también puede forzar la discusión en los términos de una disyuntiva: siempre habrá dos modos de hacer las cosas y, de ellos, uno tendrá que ser el malo y el otro, en consecuencia, será el bueno ( $c f r$. p. 75), punto en el que se aprecia la raíz de la confusión acerca de la cuestiones prácticas o normativas, a saber, el error de plantearse la decisión que se ha de tomar como la solución cabal y definitiva del problema (pp. 80-81). ${ }^{7}$ El otro rasgo señalado, la atención a las secuelas o proyecciones de las contraposiciones extremadas o indebidas, también es coherente con el análisis concreto y contextualizado de los paralogismos como casos comunes y reales, no como artificios escolares o convencionales. En el plano teórico, por ejemplo, una falsa oposición puede inducir a la trascendentalización ilegítima de una contradicción, esto es, a atribuirle una dimensión real en virtud de una confusión entre nuestros esquemas lingüísticos o mentales y la propia realidad. ${ }^{8}$ En el terreno práctico también se dejan sentir las repercusiones negativas del paralogismo que pueden traducirse en obstáculos o inhibiciones ante la

${ }^{7}$ De paso no estará de más consignar que en su planteamiento de los tres momentos en que puede dividirse el tratamiento de las cuestiones normativas - la investigación y determinación de todas las soluciones viables, el examen de sus respectivas ventajas e inconvenientes, la elección o resolución-, amén de los paralogismos que pueden anidar en ellos (1945, pp. 79-85), Vaz plantea consideraciones que hoy van siendo habituales en el estudio de la deliberación como forma de argumentación práctica y discurso público.

8 "El paralogismo consiste en atribuir a la realidad las contradicciones en que a menudo se incurre, y muchas veces es forzoso incurrir, en la expresión de la realidad; en transportar la contradicción, de las palabras a las cosas; en hacer de un hecho verbal o conceptual, un hecho ontológico" (Vaz 1979, p. 174). Confusión que propician nuestras limitaciones discursivas al tratar de forma esquemática con lo general y lo singular, y que por entonces - recordemos que este artículo de Vaz data de 1908 - había adquirido notoria actualidad. 
resolución que se ha de tomar, o en condicionamientos que sesgan la toma de decisiones. Por ejemplo, el resultado de la discusión antes mencionada en torno a la ponencia de Vaz en el Consejo Universitario fue que, dado el carácter absolutamente único y excluyente de cada uno de los procedimientos apuntados, no se podía pensar en conciliarlos, y dadas sus limitaciones respectivas, ninguno era cabalmente satisfactorio; así que al final no se hizo nada (1945, p. 27). Una secuela más general del paralogismo de falsa oposición es contribuir a hacer "de la historia del progreso intelectual de la humanidad una especie de ritmo de exageraciones" (1945, p. 41), marcado por la necesidad de formulaciones enfáticas o de pronunciamientos netos, hasta el punto de que, si alguien evita las proposiciones simplistas y rodea su propuesta de las debidas matizaciones y cautelas, corre el riesgo de no atraer la atención sobre lo que propone o de que se simplifique su posición para colocarla en una disyuntiva neta o de que, en fin, sus reservas terminen por desconcertar al público que espera un dictamen terminante o una fórmula precisa: "Pero, en resumen, al fin y al cabo, en fin de cuentas, ¿qué es lo que opina usted? ¡Decídase, resuelva!” (1945, p. 43).

Destacaré, por último, otra característica relevante del análisis de Vaz. Consiste en su ponderación y comprensión a la hora de discriminar y juzgar los efectos derivados del paralogismo. Éstos pueden ser no sólo negativos, como ya hemos visto, sino positivos, e.g., en la medida en que las contraposiciones de este tipo pueden tener virtudes estimulantes en diversos dominios del pensamiento, del arte o de la acción (1945, apéndice sobre el paralogismo de falsa oposición, pp. 43-47). Claro está que bien consideradas las secuelas de uno y otro signo, entreveradas a veces, no deja de imponerse este balance final: "que, sin perjuicio de algunos efectos estimulantes de la falsa oposición, predominan los malos; y que, además, la tendencia a reconocer y a perseguir ese paralogismo no puede producir prácticamente malos efectos" (1945, p. 47).

\section{Recapitulando: un perfil del paralogismo}

Tras haber recordado los supuestos analíticos de la Lógica viva y haber asistido al examen de un tipo concreto, creo que podemos hacernos una idea de los paralogismos según Vaz Ferreira. Los paralogismos responden básicamente al perfil siguiente:

a) Dada su dinámica y concreta condición psico-lógica, consisten en procesos, estados o disposiciones normalmente detectables y evaluables por sus síntomas, efectos o secuelas, al menos en la medida en 
que pueden darse en un nivel pre- o subdiscursivo y hacerse sentir antes que amoldarse a nuestros esquemas verbales y patrones lógicos. b) Conforman o inducen a confusiones, sesgos o distorsiones en las que se incurre con facilidad, y con menor, mayor y a menudo total inadvertencia. Se hallan muy extendidos y son difíciles de corregir, aunque algunos puedan parecer pueriles tras ser detectados.

c) Desde un punto de vista lógico y cognitivo, constituyen no sólo errores sino fuentes de error con serias repercusiones tanto en el orden del pensamiento, como en el terreno de la acción —donde pueden desembocar incluso en la inactividad, como ocurre en la discusión del Consejo Universitario antes recordada por Vaz (1945, p. 27) - . En esta perspectiva, no representan fallos o errores esporádicos, sino más bien tendencias constitutivas de vicios.

Ahora bien, en este punto, conviene reparar en que los efectos o las secuelas de las disposiciones o procedimientos matrices también pueden ser, al menos en principio, no sólo negativos sino positivos. Cierto es que, en el balance final, prevalecen y son más graves los negativos, y por ello requieren mayor atención y un tratamiento especial. Pero Vaz no deja de reconocer ese doble signo de las fuentes de paralogismos. Así, la oposición bien puede tener virtudes estimulantes a tenor del apéndice citado al final del apartado anterior; aún es más elocuente "Un paralogismo de actualidad" (1979, pp. 177-178). Creo que Vaz podría haber recordado en este sentido, por ejemplo, el protagonismo de la polarización y los servicios de conceptualización y organización del mundo prestado por los pares de opuestos en los primeros pasos del pensamiento griego, ${ }^{9}$ de modo parecido a como recuerda el papel de las contraposiciones en la física matemática moderna o el de las oposiciones legítimas e irreducibles entre ideales en conflicto. ${ }^{10}$ Es importante reparar en que esta dualidad de empleos y efectos legítimos e ilegítimos, estimulantes y perversos —virtudes

${ }^{9}$ Aparte de muestras paradigmáticas de su papel fundacional como el Poema ya mencionado de Parménides o la tabla pitagórica de opuestos, baste recordar a Aristóteles cuando cita a Alcmeón: "La mayoría de las cosas humanas se dan por pares [de opuestos]" (Metafísica, $986^{a} 31$ ), o se refiere a sus predecesores en la investigación natural: "todos ellos identifican los elementos y los que llaman principios como contrarios, aunque sin dar razones para proceder así, sino como si se vieran compelidos por la verdad misma" (Física, $\left.188^{b} 27-29\right)$. Puede verse un tratamiento detallado y comprensivo en Lloyd 1987.

${ }^{10} \mathrm{Vid}$. sus ensayos "Trascendentalizaciones matemáticas ilegítimas y falacias correlacionadas" (1939) y "Sobre interferencias de ideales en general, y caso especial de la imitación en Sudamérica" (1940), en Vaz 1956, pp. 43-65 y 141-161, respectivamente. 
y vicios_-, también se aprecia en los otros paralogismos estudiados por la Lógica viva: en la confusión entre cuestiones explicativas y normativas (1945, p. 80), el pensar por sistemas (pp. 142-143), o la falsa precisión (p. 92).

De estas complejas condiciones de diagnóstico y evaluación de los paralogismos se desprende que los juicios al respecto han de ser respetuosos con su constitución indistinta y gradual por lo regular, y los dictámenes han de ser en correspondencia sutiles y ponderados. Más aún, al tratarse de cuestiones de grados y modulaciones que se dejan sentir antes que declarar, Vaz también creerá oportuno remitir su estimación y resolución a una suerte de instinto lógico o empírico (1945, pp. 192-194), o de buen sentido hiperlógico (1945, pp. 139, 192, 199), es decir, a una disposición o un hábito de sensibilidad, susceptible de formación y refuerzo, que deberá acompañar al examen lógico y al ejercicio del razonamiento en todas las cuestiones de ese género. $^{11}$

\section{Ideas para tener en cuenta en el campo de la argumentación}

Traslademos las ideas de Vaz desde su lugar psico-lógico de origen hasta el campo actual de la argumentación para considerar sus posibles sugerencias en este terreno. No faltarán, por cierto, proyecciones sobre otros campos vecinos o, en parte, solapados - e.g., zonas de la filosofía de la lógica o de la psicología cognitiva - que no podré considerar aquí.

\section{1 .}

Para empezar, propician una visión de la argumentación como una suerte de iceberg discursivo, cuya parte oculta o "subdiscursiva" es mucho mayor que la porción visible, el argumento explícito. Pero esta imagen nos conduce hoy a la pragmática de las relaciones entre lo implícito y lo explícito antes que a la psicología supuestamente pre-

\footnotetext{
${ }^{11}$ Así, por ejemplo: "Cuando hemos visto y pesado por el raciocinio las razones en pro y las razones en contra que hay en casi todos los casos, cuando hemos hecho toda la lógica (la buena lógica) posible, cuando las cuestiones se vuelven de grados, llega un momento en que una especie de instinto - lo que yo llamo el buen instinto hiper-lógico - es el que resuelve los casos concretos. Y sería bueno que la lógica no privara a los hombres de esta forma superior de buen sentido" (1945, p. 139). Se trataría de "una especie de instinto que sale de la experiencia general, que es como un resumen y concentración de la experiencia y que nos indica más o menos, que nos hace sentir aproximadamente cuál debe ser aquel grado más justo" (p. 193).
} 
lingüística o sublingüística de la Lógica viva. ${ }^{12}$ El trasfondo marino del iceberg de la argumentación no son precisamente las corrientes de la vida mental, sino más bien el tejido lingüístico de la comunicación y la conversación entre los agentes discursivos — donde el diálogo o la deliberación de uno consigo mismo, lejos de ser el caso paradigmático, sólo es un caso derivado y límite, punto que quizás el propio Vaz habría asumido - Así pues, el traslado también llevará a modificar lo que se entiende por paralogismo o por falacia en general: ya no consistirá en una disposición o un estado del espíritu, o en un modo de pensar —y menos aún de psiquear-, sino en una actividad discursiva que tiene lugar en un contexto y con un propósito argumentativos (para dar cuenta y razón de algo a alguien, o para inducirlo a creer o hacer determinadas cosas, por ejemplo). Todo lo cual supone, en fin, contar no sólo con las dimensiones "pluriagenciales" — si se me permite la expresión — e interactivas del discurso argumentativo, sino con las perspectivas pertinentes para su visión y reconocimiento, e.g., la dialéctica o la retórica, más allá de los aspectos lógicos y psicológicos en los que se detiene Vaz Ferreira. ${ }^{13}$

\section{2 .}

Demos un paso más. En este marco argumentativo, las referencias de Vaz a los paralogismos como errores o fuentes de error en el sentido de usos o disposiciones concretas, frente a la idea tradicional de unas clases o patrones generales de falacias, suscitan un punto delicado. Sea C un contexto discursivo dado: ¿cabe distinguir entre el empleo falaz de un argumento en $\mathrm{C}$ y el empleo de un argumento falaz en C? ${ }^{14}$ Una consecuencia de la distinción sería admitir, en

${ }^{12}$ Como ya he dicho, aquí me centro en la teoría de la argumentación, sin considerar los campos limítrofes. Los interesados en la proyección de estas ideas de Vaz sobre la filosofía de la lógica pueden confrontarlas con propuestas recientes como la "protológica" de Hanna (2006). Los interesados en su poder de sugerencia para las ciencias cognitivas y la psicología del razonamiento pueden compararlas con el planteamiento actual de los sesgos, errores e ilusiones cognitivas a la luz, por ejemplo, de la miscelánea editada por Pohl (2004).

${ }^{13}$ Es sintomático que en las ocasiones en que advierte la incidencia de las maneras de presentar opiniones, planteamientos, ejemplos o argumentos, solamente se refiera a sus efectos psicológicos por contraste con los lógicos, sin contemplar su condición retórica — quizás bajo el influjo de una vieja idea de la oratoria - ; fr., por ejemplo, 1945, pp. 94-95; 145-149, 176-177, 201.

${ }^{14}$ Podría ser, en principio, una distinción semejante a la que media entre el uso impropio de un término, e.g., decir "allí estaba, te lo prometo" para significar "allí estaba, te lo aseguro", y el uso de un término impropio, un barbarismo o un neologismo inaceptable. Pero no excluye la posibilidad de casos mixtos o indecisos. 
el primer caso, la posibilidad de un uso falaz o paralogístico de un buen argumento, posibilidad no contemplada por quien se atenga únicamente al segundo caso. Vaz, a tenor de sus observaciones críticas al planteamiento de las falacias de confusión por parte de John Stuart Mill y de su insistencia en los modos concretos de incurrir en usos o estados paralogísticos, apoyaría no sólo esta distinción, sino la prioridad del primer caso sobre el segundo. Una postura más radical, favorecida por la visión de la argumentación desde el punto de vista de la retórica, lleva a reducir el segundo caso al primero al sostener que los distintos usos de un mismo (patrón de) argumento conforman y determinan en realidad distintos argumentos en sus contextos de empleo. Pero, sin dar este paso reductor, también cabe reconocer la posibilidad de casos prácticamente indistinguibles o inciertos.

\section{3 .}

Sigamos. ¿Cabría pensar en las clases o tipos reconocidos de falacias como si fueran cristalizaciones de prácticas discursivas relativamente comunes y arraigadas, antes de pasar a su registro escolar en los manuales? Esta sugerencia casaría perfectamente con algunos rasgos de los paralogismos vaz-ferreirianos: su comisión fácil y frecuente, por lo regular inadvertida; su arraigo y la dificultad de erradicarlos; su naturalidad, en suma.

Creo que además la idea podría rendir importantes servicios al estudio teórico de la argumentación falaz. Dos, en especial. Por un lado, podría contribuir a explicar el atractivo y la capacidad de confusión o el poder de engaño que normalmente se atribuye a este género de discurso. Por otro lado, podría abrir una interesante perspectiva analítica en el tema de las falacias. Ambos descansan en un mismo supuesto básico: la consideración de los paralogismos como casos o modos de mal funcionamiento de unas habilidades discursivas en las que solemos confiar. Un mal funcionamiento que, a la luz de la distinción tradicional antes recordada entre paralogismos y sofismas, puede ser más bien endógeno y "espontáneo", como el producido en el discurso monológico de un agente, o más bien exógeno e inducido como el producido en el receptor por el éxito de una estrategia sofística del emisor del discurso. Pero un mal funcionamiento que, en todo caso, no es un fallo ocasional, sino que representa una tendencia con una inversión de signo: un modo de proceder que en ciertos contextos y con ciertos usos podría tener ciertas virtudes estimulantes, en otros ámbitos de aplicación y con otros usos constituye un vicio. Según esto, lejos de reducirse a meras disfunciones, los paralogismos 
o las falacias en general constituyen confusiones habituales y errores de cierta trascendencia, amén de ser censurables como prácticas incorrectas; son vicios que piden corrección. Si la idea de virtud, bajo la invocación de unas virtudes intelectuales, se encuentra hoy bien presente en epistemología, también podemos hallar en teoría de la argumentación, concretamente en el estudio de las falacias, una idea vagamente correlativa de vicio discursivo aunque no se llame así y se considere en una perspectiva más cognitiva que discursiva: según Fogelin y Duggan, "bajo la denominación de 'falacia' criticamos cualquier procedimiento para fijar creencias que tenga una propensión inaceptablemente alta a generar creencias falsas o infundadas en relación con tal procedimiento" (1987, p. 257). Pues bien, en este mismo sentido externo - es decir al margen de las disposiciones y circunstancias concurrentes en el argumentador-, cabría trasladar el lenguaje "fiabilista" de las virtudes y los vicios al campo de la argumentación. Aquí vendría a ser virtuoso un proceso o procedimiento discursivo que, sin ser infalible, conduce normalmente y en un marco adecuado de empleo a la adopción de creencias o resoluciones fundadas y razonables. Sería un procedimiento de argumentación fiable en la medida en que, aplicado del modo apropiado en las condiciones debidas, produce por lo regular más creencias o decisiones justificadas o acertadas que injustificadas o desacertadas. Paralelamente, se entendería por vicioso o viciado, en este contexto, un procedimiento discursivo que, sin necesidad de ser deliberadamente perverso, conduce normalmente a la adopción o al mantenimiento de creencias injustificadas, o de actitudes infundadas o de resoluciones no razonables, según el asunto en cuestión. Tal sería el caso general de los paralogismos, mientras que algunos sofismas o estrategias falaces, en particular, supondrían un modo de proceder deliberadamente inductor, perverso y engañoso, de manera que por esta puerta se nos volverían a colar las relaciones de interacción y los agentes discursivos. Ahora bien, el punto crítico no radica simplemente en si estos modos falaces de proceder vulneran alguna pauta, regla o condición del buen argumentar o del argüir como es debido, según cabe suponer desde la tradición escolar sobre las falacias — pues aun concediendo que toda práctica falaz sea una mala práctica argumentativa, no se sigue que toda mala argumentación sea una falacia-. El punto más bien estriba en que esos procedimientos viciosos o viciados dan al traste con la calidad de la argumentación o de la confrontación, sesgan la interacción y obstruyen o deterioran su curso y su desenlace, en el marco discursivo dado. Las prácticas falaces en su contexto reclaman 
una vez más su entidad propia y prioritaria frente a la reglamentación o la estandarización de las falacias.

\section{4 .}

Recordemos, en fin, otro rasgo distintivo del tratamiento vaz-ferreiriano de los paralogismos para aprovechar la que aquí habrá de ser una última idea para tomar en cuenta. Se trata del cuidado y la lucidez de Vaz a la hora de ponderar tanto algunas virtudes como los claros vicios que pueden anidar en las actitudes determinantes de paralogismos: así, no olvida el valor y el poder estimulante de la contraposición, la precisión o el pensar por sistemas, al menos bajo ciertas formas y en ciertos contextos, aunque luego se echen a perder y sus perniciosas secuelas arrojen un saldo negativo. Vaz, en esta línea, da a entender que sus usos viciosos o viciados provienen de alguna suerte de extrapolación, arrogancia o exceso que convierte un procedimiento prometedor en un sesgo ruinoso. Y esto puede ocurrir, por cierto, tanto con las buenas ideas como con las buenas observaciones. ${ }^{15}$ La cuestión que entonces podría sugerir el discernimiento mostrado por $\mathrm{Vaz}$ en cuanto a las virtudes y vicios de los modos de proceder que dan en paralogismos, vendría a ser ésta: cómo es que ciertos procedimientos habituales posiblemente fiables y estimulantes, virtuosos, degeneran o se vician en ese mismo sentido discursivo y cognitivo.

No faltan en el entorno actual del estudio de las falacias indicaciones que pueden ayudarnos a situar esta cuestión en un marco teórico más básico y comprensivo. Nuestras habilidades como agentes discursivos forman parte de nuestras habilidades racionales como agentes, necesarias para nuestra supervivencia y nuestra calidad humana de vida. Estas habilidades tienen dos dimensiones o ámbitos de desempeño relevantes en el presente contexto: una cognitiva, relacionada con la información y su tratamiento, que viene a corresponder a la racionalidad teórica; otra estratégica, relacionada con el éxito de pla-

\footnotetext{
${ }^{15}$ Así, en la doctrina sistemáticamente naturalista, "una idea excelente, como es la de seguir hasta cierto punto, hasta cierto grado, según los casos, las indicaciones naturales, ha sido echada a perder, y, en vez de ser ella un instrumento de verdad, se nos ha convertido en un instrumento de error; nos ha servido, por ejemplo, para destruir o para inhibir la acción de otras muchas verdades" (1945, p. 121). O a propósito de una posición higienista que llevara a sostener una teoría de la vacuna permanente por infección continua con microbios: "una observación buena, excelente para haber hecho de ella un uso moderado y razonable, la hemos echado a perder y la hemos convertido en una causa de error, y de error funesto" (1945, p. 122).
} 
nes o proyectos y, en general, con nuestras actuaciones e interacciones con el entorno, que viene a corresponder a la racionalidad prudencial o práctica. Como agentes discursivos en una y otra dimensión, contamos con ciertos recursos, en especial información, tiempo y capacidad de procesamiento, de los que disponemos en mayor o menor grado - pero siempre limitado_- Por ejemplo, si se trata de acometer y llevar a buen término empresas científicas o tecnológicas de cierta envergadura, una comunidad o una institución establecida dispone de esos recursos en mayor grado que cualquiera de sus individuos. En todo caso, siempre dispondremos de ellos en grado limitado y habremos de actuar con información incompleta, falta de tiempo y dificultades de procesamiento - como las experimentadas, en el terreno específicamente discursivo, con condicionales, negaciones y cuantificaciones incrustadas, modalidades iteradas, probabilidades compuestas, etc.Así que nos veremos abocados, en el marco de una economía de recursos precarios, a situaciones de riesgo donde habremos de confiar en ciertas habilidades comprobadas en la ejecución de tareas, aunque nunca tengamos por lo regular el éxito asegurado. Confiaremos, por ejemplo, en polarizaciones y oposiciones para introducir cierto orden en la conceptualización del mundo o para aprovecharnos de la eficacia y la economía discursivas de pautas de argumentación como "el silogismo disyuntivo", aunque a veces nos confundan las falsas contraposiciones o se nos vaya la mano en categorizaciones de falsos opuestos, extrapolaciones y, como Vaz diría, "trascendentalizaciones" erróneas. O, para poner otro caso, seguiremos confiando en nuestra inveterada tendencia a generalizar, e.g., a efectos de identificación, previsión o prevención, aunque esto no deje de llevarnos a veces a generalizaciones precipitadas o indebidas. ${ }^{16}$ Incluso aunque las cosas pueden complicarse cuando nos movemos entre diversos contextos discursivos o cuando, por ejemplo, entramos en conflicto entre lo que no es razonable desde un punto de vista, pongamos el teórico o cognitivo, pero que sí lo sería desde el otro, digamos el práctico o estratégico. ${ }^{17}$ En esta perspectiva del fallo de funcionamiento o de

${ }^{16}$ John Woods ha insistido en este caso y en el de la estimación de probabilidades conjuntas. También propone reinterpretar las falacias tradicionales en este marco del funcionamiento precario y la actuación fallida de nuestras habilidades en la ejecución de tareas cognitivas. Véase Woods 2004, pp. 8-15 y 351 ss.

${ }^{17}$ Por ejemplo, investigaciones experimentales sobre el aprendizaje han mostrado que las ratas, tras una mala experiencia con alimentos de un sabor determinado, descartan todos los que tengan el mismo gusto aunque hayan variado las circunstancias: drástica medida que seguramente les depara más creencias falsas que verdaderas, pero puede contribuir a mejorar sus probabilidades de preservación y supervivencia 
una mala ejecución de nuestras habilidades discursivas, se explica fácilmente la naturalidad con que podemos caer en paralogismos, la dificultad de corregirlos e incluso la peculiaridad de que a veces, aun siendo casos de mal proceder discursivo, nos parezcan buenos: se trataría de una situación parecida a la de los procedimientos o los mecanismos familiares que se nos descomponen o, en nuestra torpeza, descomponemos, de modo que, en palabras de Vaz, echamos a perder una idea excelente y lo que podría haber sido instrumento de la verdad se convierte en instrumento del error (1945, p. 121). El problema es que, por lo regular y salvo en dominios restringidos de aplicación de algoritmos elementales y métodos efectivos, no disponemos ni de criterios a priori de prevención de deslices o descuidos, ni de pautas capaces de garantizar el éxito. Luego, hemos de aprender de nuestros errores, así como de nuestros aciertos o, mejor dicho, en el marco de nuestros aciertos - porque de lo contrario puede que no sobreviviéramos el tiempo suficiente para seguir aprendiendo-.

\section{Coda}

Hasta aquí, en la estela de la Lógica viva de Vaz Ferreira, nos hemos ocupado de los paralogismos y, más en especial, de los paralogismos autoinducidos, aquellos en los que el propio agente da en caer por confusión o por arrogancia o por inadvertencia. Pues bien, ¿las consideraciones y sugerencias planteadas con este propósito pueden aplicarse no sólo al resto de los paralogismos cometidos de buena fe, sino extenderse hasta el otro extremo de los sofismas y generalizarse a toda suerte de falacias? Recordemos, sin ir más lejos, el último punto: cabe pensar que las disposiciones, condiciones o estados de confusión o inadvertencia que suelen propiciar los paralogismos típicos los hacen casi invulnerables o insensibles a las políticas sistemáticas de prevención o de erradicación. ¿Tendremos mejores expectativas de prevención y defensa cuando nos enfrentamos a tramas discursivas deliberadamente engañosas, a estrategias netamente sofísticas, a argucias expresas? A la luz de la situación dada en otros campos vecinos o afines — vista, pongamos por caso, la necesidad de servirse del "razonamiento por defecto" en múltiples contextos de acción e interacción discursiva, o de dejarse guiar por "heurísticos" en teoría de la decisión o, más en general, por presunciones y reglas heurísticas

(vid. Stich 1985). En un sentido análogo cabe apreciar la prudencia preventiva de la paloma que empolla sus huevos en Alicia en el país de las maravillas (cap. 5), cuando recela de la niña que ha caído del cielo culebreando, tiene el cuello largo y reconoce haber comido huevos, al tomarla erróneamente por una serpiente. 
en diversos ámbitos del conocimiento común o científico-, considerando por añadidura la ausencia de una teoría cabal de las falacias y de criterios efectivos a priori de detección y prevención, no parece razonable esperar, al menos por ahora, medidas preventivas que nos libren definitivamente de toda suerte de deslices o nos garanticen el éxito en medio de las constantes experiencias de precariedad discursiva y cognitiva. Ni siquiera hay garantías de prever el momento en que, por decirlo en los términos pragmadialécticos de Frans van Eemeren y Peter Houtlosser, nuestros ajustes estratégicos en el curso de una discusión "derrapan" y empiezan a deslizarse por la rampa de las falacias. ${ }^{18}$ Tendremos que seguir aprendiendo. Por ejemplo, las ideas de Vaz sobre ciertas matrices de paralogismos, como la oposición excluyente o el pensar por sistemas, pueden ponernos en guardia ante posibles errores en este punto: de lo anterior no se sigue que las confusiones e inadvertencias paralogísticas se extiendan por sistema como una maldición por todo el campo de las falacias; tampoco de la inexistencia de criterios de éxito a priori se desprende la exclusión de toda posible pauta de detección y toda posible medida preventiva. En su reciente revisión general de las falacias, Christopher Tindale empieza asegurando que "los modos de evitar el razonamiento falaz, sea el debido a nosotros o sea el dirigido a nosotros, se reducen en su mayoría a algún tipo de educación" pues nacen, como ya apuntaba Aristóteles, de la inexperiencia (Tindale 2007, p. 16). Al margen del juicio que nos pueda merecer esta pedagogía - claramente insuficiente, por ejemplo, dentro de los marcos socio-institucionales de la argumentación que conforman los espacios o las "esferas" públicas del discurso_- ${ }^{19}$ lo cierto es que la Lógica viva de Vaz Ferreira sí puede ser, en efecto, sumamente ilustrativa y educativa.

El estudio de las falacias es, diríamos con Platón, hijo de Poros, la abundancia, y Penía, la penuria, una pareja de opuestos que no viven en falsa oposición. No disponemos de una definición cabal, ni de una teoría integradora de la argumentación falaz; peor aún, tampoco disponemos, ni seguramente podremos disponer, de una clasificación fina y exhaustiva de los gérmenes paralogísticos o de los especímenes sofísticos, ni de un tratamiento preciso y efectivo de

${ }^{18}$ Vid. van Eemeren y Houtlosser 2004, pp. 58-59 en especial.

${ }^{19}$ En estos marcos, ciertas condiciones concurrentes como la opacidad, la asimetría o no reciprocidad o la heteronomía de la interacción pueden determinar bloqueos, sesgos y distorsiones del discurso público, cuya neutralización exigiría acciones o medidas preventivas de carácter socio-ético y socio-político que, por lo regular, se encuentran fuera del alcance, de la competencia o la "educación" de cada individuo afectado. 
detección y prevención de sus infecciones. Pero, por otro lado, como ya mostraban los análisis y sugerencias de Vaz Ferreira en la primera mitad del pasado siglo — este año se cumple el $50^{\circ}$ aniversario de su muerte-, y desde un medio lingüístico y cultural hispano, tenemos a nuestra disposición unas cuantas ideas dignas de recordarse y de tomarse en cuenta al respecto. ${ }^{20}$

\section{BIBLIOGRAFÍA}

Doury, M. y D. Moirand (comps.), 2004, L'Argumentation aujourd'hui, Presses Sorbonne Nouvelle, París. (Hay versión en castellano en prensa: Montesinos, Barcelona, 2008.)

Eemeren, F.H. van, y P. Houtlosser, 2004, "Une Vue synoptique de l'approche pragma-dialectique", en Doury y Moirand, 2004, pp. 45-75.

Eggers, C. y V.C. Juliá, 1978, Los filósofos presocráticos, I, Gredos, Madrid.

Fogelin, R.J., y T.J. Dugan, 1987, "Fallacies", Argumentation, vol. 1, pp. 255-262.

Hanna, R., 2006, Rationality and Logic, The MIT Press, Cambridge, Mass.

Lloyd, G.E.R., 1987, Polaridad y analogía. Dos tipos de argumentación en los albores del pensamiento griego, Taurus, Madrid.

Mill, J.S., 1917, Sistema de lógica inductiva y deductiva, trad. E. Ovejero y Mauri Daniel Jorro, Madrid. [La versión en castellano es de la 6a. ed. inglesa; la la. edición data de 1843.]

Palladino, J., 1962, "La Lógica Viva y la teoría de los sofismas", Revista de la Facultad de Humanidades y Ciencias, [Montevideo], vol. 3, pp. 165192.

Pohl, R.F., 2004, Cognitive Illusions: A Handbook of Fallacies and Biases on Thinking, Judgement and Memory, Psychology Press, Hove/Nueva York.

Stich, S.P., 1985, "Could Man Be an Irrational Animal? Some Notes on the Epistemology of Rationality", Synthese, vol. 64, pp. 115-135.

Tindale, C., 2007, Fallacies and Argument Appraisal, Cambridge University Press, Cambridge.

Vaz Ferreira, C., 1979, Lógica viva. Moral para intelectuales, Biblioteca Ayacucho, Caracas. (Incluye "Un paralogismo de actualidad" (1908) y otros textos de Fermentario, amén de un prólogo de Manuel Claps y una biocronología de Sara Vaz.)

- - 1956, Algunas conferencias sobre temas científicos, artísticos y sociales, Losada, Buenos Aires.

—_ 1945, Lógica viva, 4a. ed., Losada, Buenos Aires (la la. edición data de 1910).

${ }^{20}$ Trabajo realizado en el marco del proyecto HUM2005-00365, financiado por el MEC, España.

Crítica, vol. 40, no. 119 (agosto 2008) 
Vaz Ferreira, C., 1908, “Un paralogismo de actualidad", en Vaz 1979, pp. 174-188.

Woods, J., 2004, The Death of Argument. Fallacies in Agent-Based Reasoning, Kluwer, Dordrecht.

Recibido el 16 de noviembre de 2007; revisado el 11 de junio de 2008; aceptado el 1 de julio de 2008. 